\title{
Formação de professores nas ilhas portuguesas Madeira e Açores: estratégias para o ensino remoto em tempos da COVID-19
}

\author{
Teacher training on the Portuguese islands Madeira and Açores: strategies \\ for remote teaching in COVID-19 times
}

Fernanda Araujo Coutinho Campos Doutora e Mestre em Educação (UFMG), especialista em Educação a Distância (SENAC Minas), licenciada em História (PUC Minas). Formadora, tutora, designer instrucional e consultora. Universidade Aberta - Portugal. fernanda.campos3x@gmail.com

\begin{abstract}
Rute Pereira Mestre em Pedagogia do e-Learning, (Universidade Aberta), especialista em Educação Especial (IP Santarém), licenciada em Física Química (Universidade de Aveiro), Professora de Física Química. Ministério de Educação - Portugal. rijpereira@gmail.com
\end{abstract}

\begin{abstract}
Resumo: Em tempos de Covid-19 experienciamos, por meio de um curso de formação de professores, elementos que facilitam a compreensão do que foi a adaptação das práticas educativas na educação básica. A forma de ensinar remotamente foi um processo que produziu no fazer docente modificações substanciais com relação ao uso das tecnologias e a sua aplicação nas metodologias de ensino. Foram necessárias reflexões e análises sobre as percepções vinculadas ao processo de ensino e aprendizagem remoto, utilizando tecnologias. Como foram definidas as estratégias pedagógicas docente na adaptação ao ensino remoto? Quais as práticas que foram desenvolvidas? A metodologia de pesquisa utilizada foi a qualitativa, com construções fundamentadas que comprovaram a cientificidade do trabalho. Os resultados destacam características e elementos do panorama de trabalho, com o ensino remoto emergencial facilitando reflexões e pontuando indicativos para a melhoria do que foi realizado a partir dos referenciais da área da educação a distância.
\end{abstract}

Palavras-chave: Ensino e aprendizagem. Docência online. Formação de professores. Estratégias de ensino. Ensino remoto.

Abstract: In Covid-19 times we experienced, through teacher training course, elements that facilitate the understanding of what was the adaptation of educational practices in basic education. The way of teaching remotely was a process that produced in the teacher substantial modifications regarding the use of technologies and their application in teaching methodologies. Reflections and analyses were needed on the perceptions linked to the teaching process and remote learning, using technologies. How were teaching strategies defined in the adaptation to remote teaching? What practices were developed? The research methodology used was qualitative, with substantiated constructions that proved the scientificity of the work. The results highlight characteristics and elements of the work panorama, with the emergency remote teaching facilitating reflections and scoring indicators for the improvement of what was done from the benchmarks in the area of distance education.

Keywords: Teaching and learning. Online teaching. Teacher training. Teaching strategies. Remote teaching. 


\section{Introdução}

O confinamento e a suspensão das atividades escolares presenciais, decorrentes da crise sanitária originada pela pandemia da Covid-19, exigiram mudanças rápidas e emergenciais para garantirem a continuidade dos processos educativos, de forma abrangente e igualitária. As tecnologias digitais e as experiências de educação a distância foram logo apontadas como soluções para que a educação não parasse, independentemente da duração do estado de emergência.

Foi em meados de março de 2020 que a maior parte das escolas encerraram as suas atividades presenciais em todo o mundo. A pandemia alastrou-se rapidamente, não havendo tempo para grandes planos. As ações eram realizadas ponto a ponto, com os recursos que os professores e as famílias dispunham. Mesmo com as portas das instituições escolares fechadas, a educação não parou. Professores, gestores, pais e estudantes tiveram que reorganizar as suas rotinas, os seus espaços de aprendizagem e os seus modos de ensinar e de aprender.

Em Portugal, o encerramento das atividades escolares presenciais ocorreu em 15 de março de 2020, tendo como medida inicial a continuação das aulas por intermédio das tecnologias digitais. O Governo promoveu ações para garantir a continuidade do período letivo, como a criação de canais no Youtube e a transmissão de teleaulas especiais pelo canal televisivo RTP Memória².

No âmbito legal, o decreto n. 14-G/2020³, publicado em 13 de abril, estabeleceu as medidas excepcionais e temporárias na área da educação, no contexto da pandemia da Covid-19.

Para além disso, o governo tentou apoiar pais ${ }^{4}$ e estudantes ${ }^{5}$ com o lançamento de campanhas publicitárias, divulgadas em meios digitais e analógicos, aconselhando-os a acompanhar os estudos dos filhos.

No que toca aos professores, organizaram-se institucionalmente e também ocuparam as redes sociais para trocar informações, partilhar conhecimentos e experiências, tanto em grupos tal como em comunidades no Facebook. O exemplo, mais evidente, em Portugal, foi a criação do Grupo E-learning Apoio ${ }^{6}$.

Dentre os desafios encontrados pelos docentes, no contexto da pandemia, para a continuação das atividades escolares, estavam: a formação para o uso das tecnologias digitais da informação e da comunicação na educação, como, também, o acesso à internet e aos equipamentos para todos os estudantes. $\mathrm{Na}$ perspectiva de apoiar as escolas no desenvolvimento do ensino a distância, a Direção Geral da Educação (DGE) organizou, em parceria da Universidade Aberta (UAb - Portugal), uma formação destinada aos diretores escolares, professores e coordenadores. Denominada "Formação para a Docência Digital em Rede", essa capacitação profissional, foi realizada on-line, durante 3 semanas, com momentos síncronos e assíncronos para apresentar os 
seguintes temas: Educação e Comunicação Online e Modelos Pedagógicos Virtuais; Plataformas e Tecnologias Digitais Online e E-Atividades de Aprendizagem e, Avaliação Digital. Será essa a experiência a ser relatada neste artigo, mais especificamente, a realização da referida formação durante os meses de junho e julho de 2020, com os professores e diretores de escolas das ilhas portuguesas - Madeira e Açores. O curso realizado objetivou a orientação para a docência online, de forma emergencial, ao mesmo tempo que buscou sensibilizar o uso das tecnologias para os processos de ensino e aprendizagem.

Nessa direção, informamos que os objetivos deste artigo se centraram em observar as práticas educativas realizadas durante a primeira fase da pandemia, no contexto português; relatar a experiência de um curso de formação de professores para a docência online, retratando as apreciações e impressões dos docentes das ilhas portuguesas. Deste modo, o intuito é partilhar informações e conhecimentos verificados que possam ser aprimorados e analisados a partir da realidade vivenciada com os fundamentos da educação online.

Nos últimos meses, foram publicadas reflexões e iniciativas das experiências imediatas que atendem a situação de emergência. Aqui, o nosso intuito está em aprofundar o tema sob o prisma do docente, sua percepção em relação as limitações e as dificuldades sentidas sobre o "como fazer" e a qualidade do processo. Como proceder? De que forma realizar a transição? Quais as principais necessidades? Enfim, essas e outras questões foram consideradas as primordiais no processo disruptivo realizado.

Nesse sentido, a justificativa deste artigo está em analisar o contexto do que foi denominado de ensino remoto de emergência, nos seus fundamentos educativos, desde os conceitos, até o trabalho empírico realizado durante a pandemia. Para isso, a estrutura do texto será: "O Contexto da pandemia"; "Metodologia do estudo realizado"; "Caracterizando a Formação para Docência Digital em rede"; "Resultados e discussões" e, "Considerações finais".

\section{$2 O$ contexto da pandemia}

A China, como o primeiro país a enfrentar a crise da Covid-19, destacou que a escola, por ser um espaço de formação das novas gerações para a integração social, cultural e econômica, não poderia prescindir de saberes e práticas vinculadas ao uso e apropriação de tecnologias digitais. Assim, as tecnologias foram o recurso encontrado para resolver a situação imposta pela pandemia no contexto educativo. Essa resolução foi considerada por alguns como a salvadora da situação e, por outros, o único caminho a ser utilizado mediante a falta de outras opções. Considerando opiniões tão opostas, cabe agora entender o verdadeiro papel das tecnologias no contexto da 


\section{Dialogia}

CAMPOS, Fernanda Araujo Coutinho; PEREIRA, Rute. Formação de professores nas ilhas portuguesas

Madeira e Açores: estratégias para o ensino remoto em tempos da COVID-19

educação. Na realidade, esse tema tem sido, há muitos anos, discutido e fundamentado em diversas investigações, dentro e fora da área da educação.

Diante da situação instaurada, a continuidade do processo de ensino-aprendizagem coube às tecnologias disponíveis. Diversas vezes questionada e renegada, esse sistema esteve em cena e, inegavelmente, foi aplicado. Dessa forma, ele deve ser analisado para prosseguir em uso, no contexto que ainda persiste nesse momento.

A partir dessa introdução, para iniciar as reflexões, destacamos, a seguir, a Figura 1. Disponibilizada pela UNESCO, essa figura representa um mapa de monitoramento do funcionamento das escolas em escala global. Através dele, é possível visualizar a dimensão da situação na qual as escolas se encontraram e refletir sobre o que se originará a partir disso, tal como forma que a pandemia afetou e afetará a geração atual.

Figura 1 - Mapa de monitoramento do funcionamento das escolas em escala global: Impacto da Covid-19 na Educação
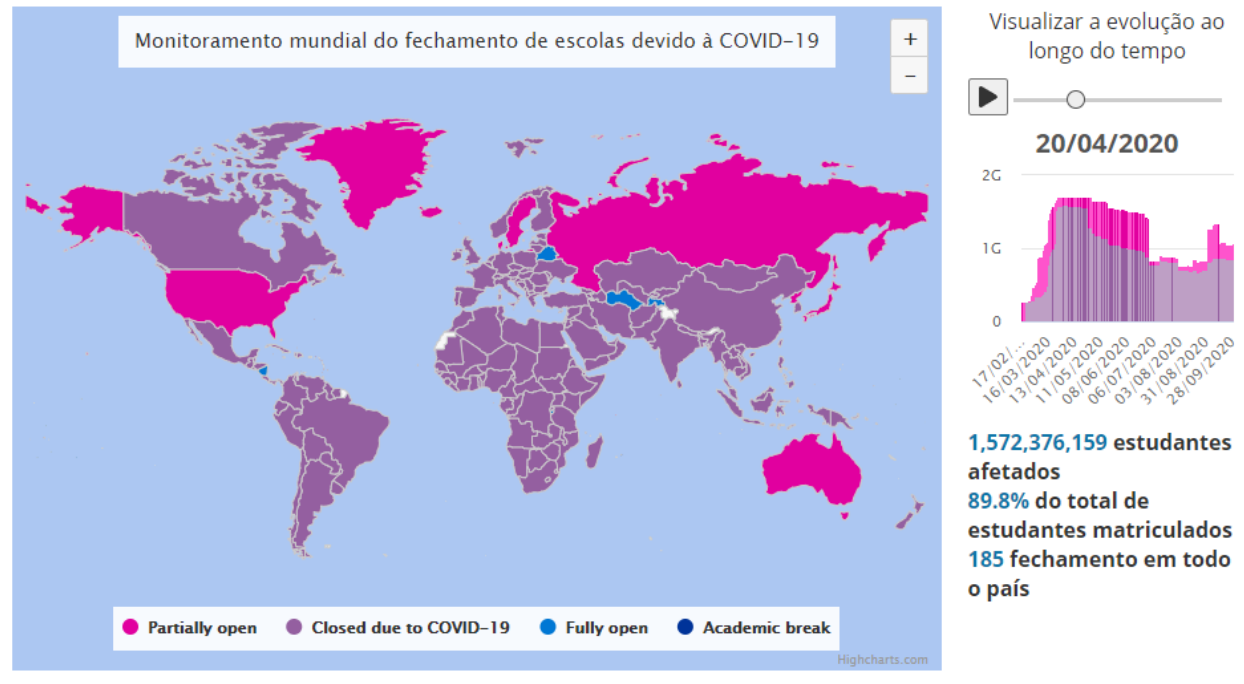

Fonte: UNESCO (2020)7.

O monitoramento dos dados da UNESCO, sobre o fechamento das escolas, foi iniciado em 17 de fevereiro de 2020. Destacamos que a imagem acima demonstra um dos momentos de pico mundial da doença, que impactou a vida de cerca de $90 \%$ dos estudantes ao redor de todo o mundo.

Neste momento pandêmico, constituiu-se algo novo que foi denominado como "ensino remoto emergencial", que se caracteriza por 
aulas que são transmitidas em tempo instantâneo por sistemas de webconferência, as chamadas lives, que permitem que professores e alunos tenham condições de realizar interações e organizarem seus tempos de aprendizagem da forma mais próxima à educação presencial (ARRUDA, 2020, p. 262).

Os autores Hodges et al. (2020) destacam aspectos mais reflexivos sobre o tema, enfatizando que o ensino remoto emergencial é uma mudança temporária para um modo alternativo, devido às circunstâncias da crise. Essa modalidade, envolve o uso de soluções totalmente remotas que, de outra forma, seriam ministradas presencialmente ou como cursos híbridos. O objetivo, durante uma emergência ou crise, nessas circunstâncias, não é recriar um sistema educacional robusto, mas fornecer acesso temporário a suportes e conteúdos educacionais de maneira rápida, fácil de configurar e confiável.

É essencial ressaltar que o ensino remoto emergencial, embora também pautado no uso das tecnologias de forma ampla, não é o mesmo que educação a distância ou online. Partindo dessa premissa, o chamado ensino remoto deverá ser aprimorado para atingir uma série de preceitos necessários para que se tenha o desenvlvimento de um processo qualitativo, na prática educativa.

Inegavelmente, o ensino remoto foi a forma encontrada pelas instituições de ensino de todo o mundo, para continuaram funcionando, diante do fechamento das escolas, em decorrência da pandemia da Covid-19. O que foi colocado em prática, é algo inédito que se apresentou com características próprias e distintas daquilo que se entende por educação a distância. A título de comparação, vejamos o Quadro 1. 
Quadro 1 - Comparação entre a Educação a Distância e ło Ensino remoto emergencial Educação a Distância Ensino Remoto Emergencial

\begin{tabular}{|c|c|}
\hline Tecnologias com uma intencionalidade pedagógica. & Tecnologias para solucionar a não-presencialidade. \\
\hline Momentos síncronos e assíncronos. & Prioritariamente momentos síncronos. \\
\hline Flexibilidade espaço-temporal. & $\begin{array}{l}\text { Exigência de momentos síncronos, de acordo com a } \\
\text { carga horária escolar. }\end{array}$ \\
\hline $\begin{array}{l}\text { Momentos pedagógicos para interação com o docente, } \\
\text { com o conteúdo entre os estudantes. }\end{array}$ & Momentos de interação com o docente. \\
\hline Planejamento e preparação com antecedência. & $\begin{array}{l}\text { Pouco ou nenhum planejamento, uma ação temporária } \\
\text { entregue como uma alternativa para os tempos de } \\
\text { confinamento. }\end{array}$ \\
\hline $\begin{array}{l}\text { Apoio de tutores e equipe técnica para dúvida e } \\
\text { dificuldades. }\end{array}$ & Apoio docente síncrono. \\
\hline Público-alvo majoritário: adultos. & $\begin{array}{l}\text { Público-alvo majoritário: todos os estudantes sem aulas } \\
\text { (desde a educação infantil à pós-graduação). }\end{array}$ \\
\hline Autonomia. & Apoio das famílias. \\
\hline Planos legalmente autorizados. & Planos de emergência. \\
\hline $\begin{array}{l}\text { Numerosos estudos, teorias, modelos, normas e critérios } \\
\text { de avaliação; focados na qualidade da aprendizagem. }\end{array}$ & $\begin{array}{l}\text { Metodologia de ensino presencial mediada pelas } \\
\text { tecnologias digitais de comunicação. }\end{array}$ \\
\hline $\begin{array}{l}\text { Presença marcada por participação nos fóruns e } \\
\text { cumprimento das atividades. }\end{array}$ & Presença síncrona sugerida. \\
\hline
\end{tabular}

O que fica claro é que as características identificadas no Ensino Remoto, por vezes, contradizem os benefícios da EaD, como por exemplo, a falta de flexibilidade temporal, a organização dos processos de comunicação síncronos e assíncronos, a interação e o planejamento específico para o online.

Mesmo com as críticas, o ensino remoto foi uma forma de manter o vínculo entre estudantes, professores e demais profissionais da educação, conforme nos recorda Arruda (2020). Assim, poderia 
representar o afastamento, por muitos meses, de estudantes dos espaços escolares (físicos e virtuais), o que pode comprometer a qualidade da educação, possivelmente mais do que a implantação de iniciativas que mantenham docentes e estudantes vinculados, apesar das limitações que venham a conferir. (ARRUDA, 2020, p. 266).

Moreira, Henriques e Barros (2020) concordam que este foi um período importante de transição. Foi um momento em que os professores foram provocados a se transformar em Youtubers, conhecer e utilizar ferramentas de comunicação síncrona e plataformas de aprendizagem. No entanto, muitas vezes, as tecnologias ainda foram utilizadas de forma meramente instrumental. Dessa maneira, esses autores acreditam que é urgente e necessário transitar deste ensino remoto de emergência, importante numa primeira fase, para uma educação digital em rede, de qualidade. Mais do que a transferência de práticas presenciais, urge agora a criação de "modelos de aprendizagem virtuais que incorporem processos de desconstrução e que promovam ambientes de aprendizagem colaborativos e construtivistas nas plataformas escolhidas" (MOREIRA, HENRIQUES, BARROS, 2020, p. 352).

$\mathrm{Na}$ esteira dos mesmos autores, entendemos que a

educação digital em rede, um processo que se caracteriza pela conectividade, rapidez, fluidez, apropriação de recursos abertos e de mídias sociais é necessário desencadear processos educativos destinados a melhorar e a desenvolver a qualidade profissional dos professores. É preciso que tenhamos consciência, o que significa sentir e responder ao mundo com conhecimento (MOREIRA, HENRIQUES, BARROS, 2020b, p. 3)

Para uma educação digital em rede ser de qualidade, vários elementos estruturantes necessitam ser considerados e direcionados pelos planos estratégicos das políticas locais.

No caso do ensino remoto, Justin (2020) ressalta os elementos de sustentabilidade de um plano que considere a situação e as necessidades emergentes, como: a obrigatoriedade em oferecer algum tipo de apoio com o fecho das instituições educativas - algo que dê suporte os docentes, estudantes e pais neste contexto; dar atenção à equidade e ao acesso, considerando que muitas famílias não podem ou não têm facilidade de acesso à internet, sendo necessário encontrar alternativas como o uso da televisão, materiais impressos ou outras possibilidades a serem discutidas e pensadas; novos requisitos de avaliação, de acordo com a configuração de tempo de aprendizagem; nova dinâmica de trabalho; atenção aos estudantes com necessidades especiais, para as novas adaptações a serem realizadas, e também a atenção às crianças vulneráveis. Considerando esses como alguns dos elementos a serem contemplados, se pode pensar numa educação digital de maior qualidade e com diretrizes fortalecedoras das suas dimensões.

A educação digital em rede, de qualidade, se define, por sua vez: "por uma concepção própria de docência em contextos online; por um formato das práticas pedagógicas ativas e 
construtivistas, que sustentam um conhecimento coletivo; por uma aprendizagem colaborativa" (MOREIRA, HENRIQUES, BARROS, 2020); "por uma concepção de comunicação que englobe possibilidades síncronas e assíncronas” (MOREIRA; BARROS, 2020); pela ampliação da consciência para ser um docente online, com o uso de tecnologias e ferramentas anteriormente não contempladas; pela gestão da informação na sala de aula virtual em suas diversas dimensões; por estratégias de ensino e aprendizagem; e por novos formatos de avaliação e presencialidade, contadas pela participação e interação com os estudantes.

Foi considerando os referidos aspectos, em termos estruturais e de qualidade, que a Formação para a Docência Digital e em Rede foi organizada e ofertada pela Universidade Aberta (UAb) para diretores, professores e coordenadores em Portugal.

\section{Metodologia do estudo realizado}

O presente trabalho enquadra-se num paradigma qualitativo, sendo que, para tal, os procedimentos metodológicos utilizados foram de base teórica e empírica, a partir das experimentações do trabalho pedagógico realizado na referida formação, juntamente com produções já desenvolvidas e em curso.

O contexto utilizado para este estudo foi a Formação para a Docência Digital e em Rede, realizada pela Universidade Aberta, em Portugal, em parceira com a DGE, para docentes da educação básica e de escolas públicas, diretores e coordenadores, na oferta para as Ilhas da Madeira e dos Açores. A formação, em tela, ocorreu no período de junho a julho de 2020, com a inscrição de mais de duzentos professores, completamente online, utilizando-se o modelo pedagógico da Universidade Aberta e seu know-how na área da docência online.

A recolha de dados ocorreu de forma livre por meio de um questionário online, após consentimento dos respondentes. Os questionamentos estavam centrados em: entender o perfil daqueles professores em formação; verificar de que modo utilizavam as tecnologias digitais em suas aulas antes e durante a pandemia e, verificar a pertinência da formação para a sua prática docente.

Os formandos foram convidados a responder o questionário, organizado em 37 questões, divididas em quatro seções, a saber: informações pessoais, educação, metodologia e tecnologias, educação durante e pós-pandemia e avaliação do curso. Atendendo aos objetivos deste artigo, selecionamos as três primeiras sessões, que nos deram condições para caracterizar o perfil dos formandos e a maneira como utilizaram as tecnologias digitais pessoalmente e em suas estratégias pedagógicas. Reiteramos que o questionário foi disponibilizado para os 341 inscritos na referida 
formação. A amostra do questionário limitou-se a cerca de $30 \%$ do total, o equivalente a 109 respondentes.

Após a coleta dos dados, a análise foi realizada com estatística simples e descritiva, articulando as evidências aos fundamentos práticos e teóricos selecionados como referências para este estudo.

\title{
3.1 Caracteriżando a Formação para Docência Digital em rede
}

Nesse contexto emergente, foi preciso estruturar de forma rápida uma formação que proporcionassem respostas e assistências para as mudanças estruturais vivenciadas. A Formação para Docência Digital em Rede se constituiu como uma das iniciativas da própria estrutura ministerial portuguesa, para colmatar o déficit a que os docentes ficaram sujeitos no ensino remoto.

Esse curso foi organizado pela Universidade Aberta em Lisboa, Portugal. Uma instituição pública de ensino a distância e e-learning, com mais de trinta anos de experiência na área e com um modelo pedagógico único, premiado e respeitado no contexto da lusofonia.

A formação foi organizada em três temas, desenvolvidos semanalmente, a saber: Educação e Comunicação Online e Modelos Pedagógicos Virtuais; Plataformas e Tecnologias Digitais Online; E-atividades de Aprendizagem e Avaliação Digital Online. A previsão de estudos era de 26 horas.

Ao final, esperava-se que os formados fossem capazes de:

\begin{abstract}
conhecer os novos desafios da docência digital em rede relacionados com os diferentes espaços e ambientes personalizados de aprendizagem; analisar processos de comunicação e interação em contextos de docência digital em rede; conhecer diferentes modelos pedagógicos para contextos de docência digital em rede; desenhar e desenvolver eatividades em ambientes digitais de ensino-aprendizagem em rede; conhecer e utilizar plataformas e tecnologias digitais, numa ótica comunicativa e educacional (MOREIRA, HENRIQUES; BARROS, 2020b, p. 3).
\end{abstract}

Os materiais (materiais online, vídeos, e-books, textos de orientação, recursos abertos e material multimídia) estavam disponíveis na plataforma Moodle; a comunicação acontecia maioritariamente de forma assíncrona, por meio de fóruns em cada um dos módulos que proporcionaram o debate e o diálogo entre os formandos e os tutores; os três encontros síncronos foram transmitidos no Youtube 8 pelo canal institucional da Universidade Aberta. Para concluir o curso com aproveitamento e obter a respectiva certificação, o formando teria que participar nas salas de aula (fórum de debate) disponíveis, nos temas 1, 2 e 3, e elaborar o trabalho final, que se deveria traduzir numa e-atividade. 


\section{Dialogia}

CAMPOS, Fernanda Araujo Coutinho; PEREIRA, Rute. Formação de professores nas ilhas portuguesas Madeira e Açores: estratégias para o ensino remoto em tempos da COVID-19

\subsection{Resultados e discussões}

Reiteramos que tivemos 109 respondentes do questionário. Dentre os inquiridos, os formandos da ilha da Madeira que tiveram uma maior expressão, sendo 70 respondentes dessa Ilha e 39 da Ilha dos Açores. Dos participantes, 70 eram do sexo feminino e 38 eram do sexo masculino, considerando que uma pessoa não identificou o gênero. Na média, os respondentes encontram-se na faixa dos 45 anos de idade, com 20 anos de experiência na área da educação. Entre os respondentes, 94 participantes eram docentes, 14 gestores e 4 pessoas trabalhavam na biblioteca.

As áreas de atuação docentes foram identificadas no Gráfico 1, que apresenta a distribuição por grupos de recrutamento?:

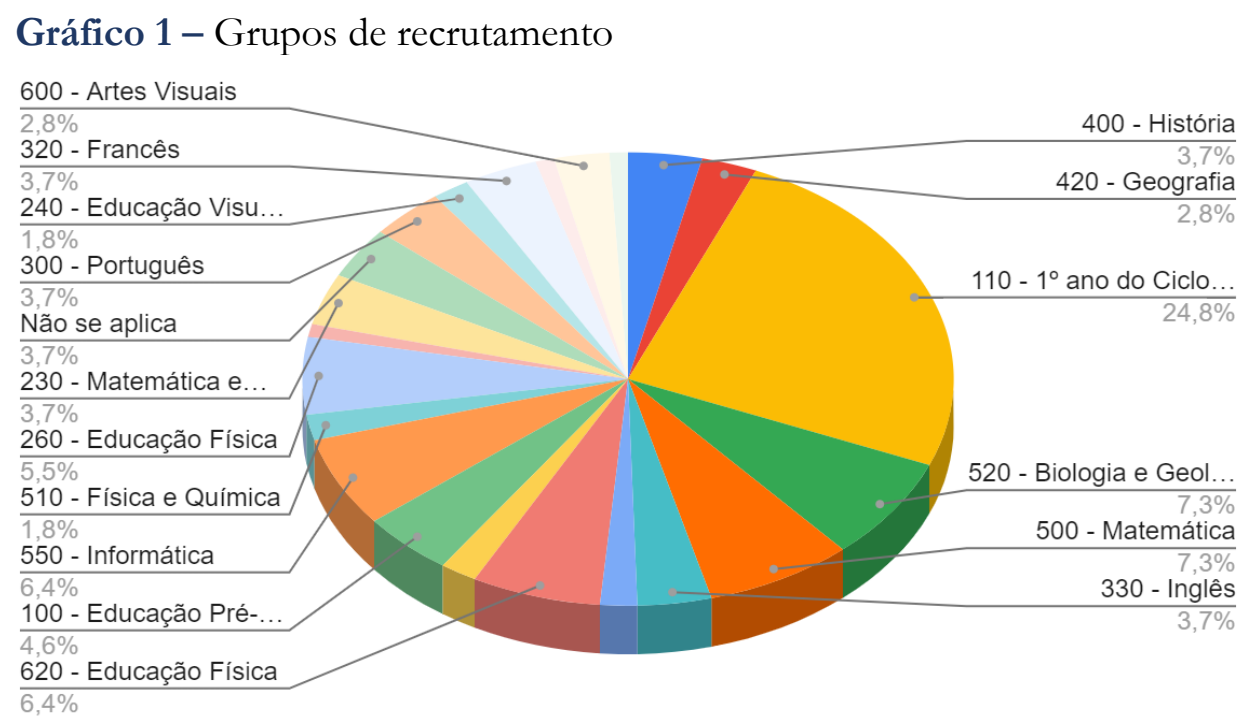

Fonte: Dados da pesquisa (2020).

Verificamos que a maior parte dos docentes lecionavam no $2^{\circ}$ ciclo e ensino secundário ${ }^{10}$. Alguns dos professores também atuavam no ensino superior, ensino profissional e educação préescolar. Maioritariamente, tínhamos docentes das diversas áreas e que atuavam diretamente com uma população pré-adolescente, já experiente - ao menos - no uso das tecnologias para o entretenimento.

Para entender o tipo de tecnologia que os docentes utilizavam nas suas rotinas pessoais, questionamos as preferências e os canais de comunicação online que os professores possuíam. Verificamos que quase a totalidade dos respondentes utilizou as redes sociais como o principal canal de comunicação online. Também encontramos 43 respondentes mais imersos no mundo virtual, com blog/sites pessoais, blog/sites profissionais e canais no Youtube, ao mesmo tempo que 5 participantes assumiram-se desconectados de todo e qualquer canal de comunicação online. 


\section{Dialogia}

CAMPOS, Fernanda Araujo Coutinho; PEREIRA, Rute. Formação de professores nas ilhas portuguesas

Madeira e Açores: estratégias para o ensino remoto em tempos da COVID-19

Esse perfil de uso das redes é bastante significativo quando se trata de comunicação, acesso e dinamização das relações, mas o que observamos é que essa experiência relatada não foi de todo transposta para o contexto da prática pedagógica. Somente alguns elementos puderam ser observados, como, por exemplo, a iniciativa de utilizar essas mesmas redes para comunicar com os estudantes, criar comunidades e espaços de interação.

Os Gráficos 2 e 3 ilustram os resultados em relação às redes sociais, e a comparação com a questão das ferramentas mais utilizadas com os estudantes no processo de comunicação. A grande surpresa é que, mesmo sendo os professores utilizadores das redes sociais, não houve uma adaptação à necessidade emergente de comunicação com os próprios estudantes. É importante ressaltar que o uso cotidiano dos canais de comunicação nos possibilita empiricamente um importante referencial para ser aplicado no fazer pedagógico. É nesse processo de transposição que se encontra a grande dificuldade docente e a necessidade de formação, conforme Ribeiro e Barros (2019).

Gráfico 2 - Canais de comunicação online de uso pessoal

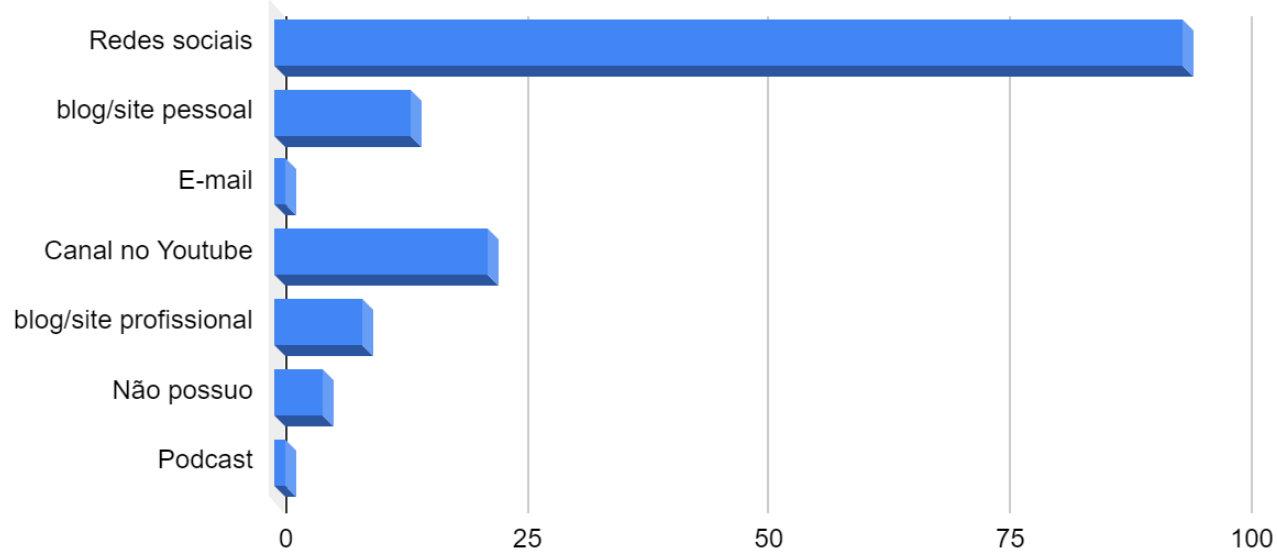

Fonte: Dados da pesquisa (2020). 


\section{Dialogia}

CAMPOS, Fernanda Araujo Coutinho; PEREIRA, Rute. Formação de professores nas ilhas portuguesas

Madeira e Açores: estratégias para o ensino remoto em tempos da COVID-19

Gráfico 3 - Ferramentas de Comunicação mais utilizadas com os estudantes

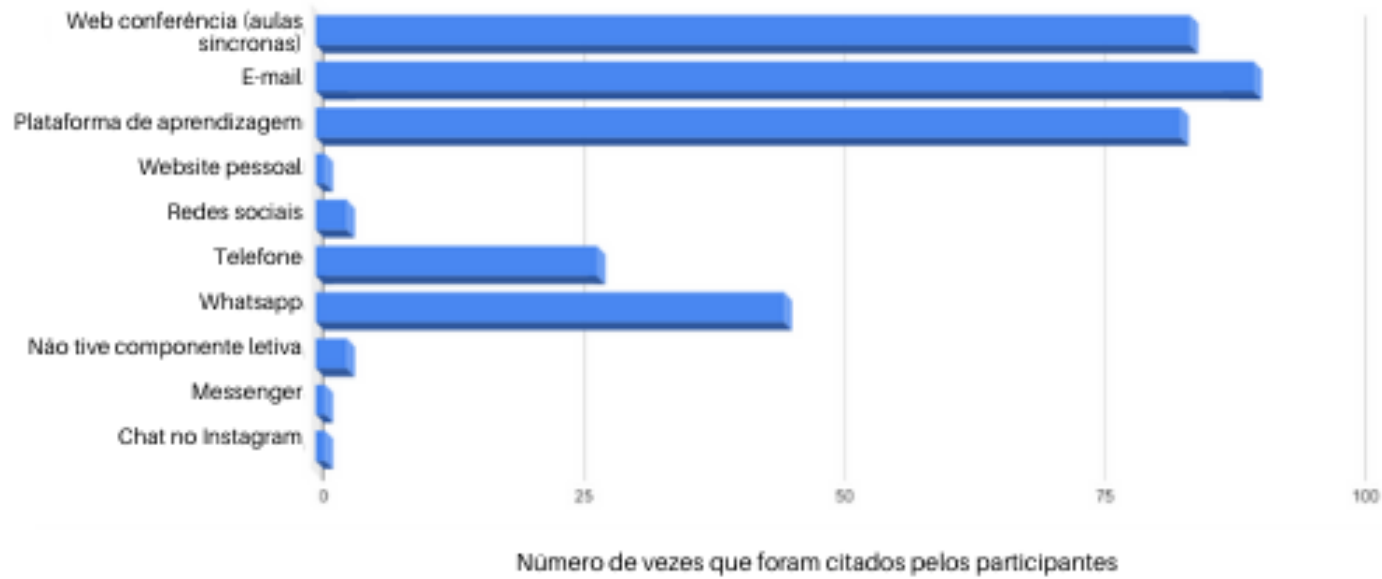

Fonte: Dados da pesquisa (2020).

Quando questionados se consideravam que, durante o tempo de isolamento, houve aprendizagem por parte dos estudantes, $76 \%$ dos professores, achou que sim, ocorreu aprendizagem; apenas 15\% não conseguiu avaliar, especificamente.

A oferta do curso, Formação Docência Digital em Rede, foi realizada entre 29 de junho e 15 de julho 2020, período correspondente à entrega de notas e finalização do ano escolar. Esta informação é significativa, pois, reconhecendo o esforço dos professores - mediante o aumento de afazeres - a dedicação e a entrega que realizaram, demonstra que eles acreditam na força do seu trabalho, independentemente da forma de ensinar.

É inegável o esforço dos professores e de como todos esses procuraram fazer o melhor que conseguiam, mesmo que nunca antes tivessem trabalhado com o ensino online. Grande parte utilizava as tecnologias dentro de práticas específicas, e não como meio quotidiano para o processo de ensino e aprendizagem.

Questionamos se os aprendizados da Formação seriam aplicados na prática: $80 \%$ dos respondentes disseram que sim. Demonstrando, desta forma, que o conteúdo elegido estava de acordo e atendia a expectativa de grande parte dos formandos.

Esse relato de experiência in loco finaliza-se com as seguintes análises, a partir dos resultados do questionário e da experiência aqui desenvolvida: houve um grande esforço em envolver ativamente os discentes na sua própria aprendizagem, mas nem sempre foi fácil para os jovens estudantes que, na sua maioria, preferem ser um elemento passivo na sala de aula, em que não tenham de exercitar, refletir, explorar. Curiosamente, esse fato evidenciou-se na aplicação final de 
um questionário de avaliação, realizado na última semana de aula que tiveram antes das férias do meio do ano. Os estudantes manifestaram maior interesse e gosto pelas tarefas estanques, tais como pela elaboração dos questionários.

Em comparação com os resultados dos questionários, foi possível verificar que as preocupações dos docentes não estavam alinhadas com o que os estudantes necessitavam. As descobertas foram ocorrendo durante o processo. O questionário demonstra a não-preparação do professor para o trabalho que precisou realizar e também os problemas do que consideraram como as melhores opções. Da parte do estudante, o questionário demonstra a dinâmica do fazer atividades somente como interesse por notas e avaliação. Ambos elementos desalinhados da necessidade e das bases de uma prática docente online, qualitativa e coesa para os processos de ensino e aprendizagem.

\section{Considerações finais}

"Educação: a mudança é a única constante". Este é título do capítulo da obra de Harari (2018), que apresenta lições para a educação no século XXI. Apesar desse trabalho ter sido publicado há mais de dois anos, ele apresenta questões para uma educação do futuro, mencionando questões pertinentes, tais como: qual deverá ser a educação de 2050? Qual será o uso das tecnologias? Das metodologias ativas? Entre outras. O ano de 2020, marcado pela crise de saúde pública mundial da Covid-19, trouxe outras perspectivas e impôs uma adaptação a novas formas de ensinar e de aprender. Reorganizou espaços e colocou em larga escala a necessidade do ensino remoto.

Durante os meses em que as escolas estiveram fechadas, a educação não parou. Continuou do modo que foi possível, com os caminhos sendo continuamente lapidados. As escolas não possuíam manual, nem práticas de ensino com a mediação de tecnologias em larga escala, que foram utilizadas como solução temporária, em erros e acertos.

Identificamos, dentro de um curso concentrado de formação de professores para a docência online, elementos que facilitam a compreensão do que foi a adaptação das práticas educativas na educação básica, no contexto das ilhas portuguesas.

As estratégias pedagógicas docentes aplicadas no ensino remoto e as práticas desenvolvidas, foram uma adaptação empírica de uma realidade emergente. Os resultados destacaram características e elementos do panorama de trabalho, com o ensino remoto emergencial facilitando reflexões e indicativos para a melhoria do que foi realizado. 
CAMPOS, Fernanda Araujo Coutinho; PEREIRA, Rute. Formação de professores nas ilhas portuguesas

Diante dessa vivência coletiva, fica a experiência, a reflexão sobre as práticas e a construção de um caminho por uma educação digital em rede, que era o objetivo da formação realizada. Sabemos que muitas necessidades ficaram sem respostas. $\mathrm{O}$ acesso a equipamentos e a rede de dados é uma dificuldade para muitos. No ano de 2020, encontramos possíveis soluções, realizamos novas combinações de ensino e aprendizagens e, mesmo com tantas incertezas, ficou o aprendizado e a visão de que precisamos, sim, ressignificar a educação, repensar as metodologias, os papéis de professores e estudantes, as relações e o uso das tecnologias digitais. Se antes isso podia ser visto como uma tendência, hoje, a pandemia revelou como uma necessidade e, amanhã, se consolidará como parte intrínseca de qualquer formação na área da educação.

\section{Notas}

${ }^{1}$ Canal DGE ME \#estudoemcasa. Disponível em: https://www.youtube.com/channel/UCDM1UhWp9gUPSGWMXP6EwWQ. Foram criados 5 canais para atender os estudantes do pré-escolar ao ensino secundário. Nessa plataforma os professores poderiam fazer uma curadoria de vídeos ou criar e publicar os seus próprios vídeos.

2 As tele aulas integraram a programação no Canal RTP Memória, de segunda a sexta-feira, das 9:00 às 17:50, e também disponível pelo site: https://www.rtp.pt/play/estudoemcasa/.

${ }^{3}$ Decreto n. 14-G/2020. Disponível em: https://dre.pt/application/conteudo/147933283 acesso em 20 nov. 2020

${ }^{4}$ Ministério da Educação lança vídeo com conselhos para os pais https://www.dge.mec.pt/ noticias/covid-19ministerio-da-educacao-lanca-video-com-conselhos-para-os-pais.

${ }^{5}$ Neste caso, convidaram um Youtuber para atingir o público jovem, como conselhos para os estudantes https://www.youtube.com/watch?v=X7UY2tIJA9k\&feature=emb_logo.

${ }^{6}$ Em outubro de 2020 o número de participantes era de 31.700 inscritos. Disponível em: https://www.facebook.com/groups/eLearningApoio.

${ }^{7}$ Disponível em: https://pt.unesco.org/covid19/educationresponse.Acesso em 15 de outubro de 2020.

${ }^{8}$ Canal Youtube ELO - Unidade Móvel em Estudos do Local. https://www.youtube.com/channel/UCo5Spl3b5LoVMZBXawsaxIA.

${ }^{9}$ Em Portugal os Grupos de Recrutamento são definidos pelos Decretos: (Decreto-Lei n. ${ }^{o}$ 27/2006, de 10 de fevereiro, alterado pelos Decretos-Lei n. ${ }^{\circ}$ 176/2014, de 12 de dezembro e n. ${ }^{\circ} 16 / 2018$, de 7 de março). Podem ser consultados em: https://www.dgae.mec.pt/?wpfb_dl=31789. Acesso em 12 de outubro de 2020.

10 A Educação em Portugal está assim organizada: Educação Pré-escolar, Educação Básica $\left(1^{\circ}\right.$ e $2^{\circ}$ ciclo, corresponde do $1^{\circ}$ ao $9^{\circ}$ ano), Ensino Secundário $\left(10^{\circ}\right.$ ao $12^{\circ}$ ano), Ensino Profissional e Ensino Superior. Informações disponíveis em: https://www.dge.mec.pt/. Acesso em 12 de out. 2020.

\section{Referências}

ARRUDA, Eucídio Pimenta. Educação remota emergencial: elementos para políticas públicas na educação brasileira tem tempos de COVID-19. EmRede, v. 7, n. 1, p. 257 - 275, 2020. Disponível em: https://www.aunirede.org.br/revista/index.php/emrede/article/view/621. Acesso em 14 set. de 2020 . 


\section{Dialogia}

CAMPOS, Fernanda Araujo Coutinho; PEREIRA, Rute. Formação de professores nas ilhas portuguesas Madeira e Açores: estratégias para o ensino remoto em tempos da COVID-19

CAMPOS, Fernanda Araujo Coutinho. A educaşão em tempos de pandemia, 2020. Disponível em: https://observatoriodacomunicacao.org.br/colunas/a-educacao-em-tempos-de-pandemia-porfernanda-campos/. Acesso em 14 set. de 2020.

HARARI, Yuval Noah. N. 21 lições para o século XXI. Portugal: Elsinore, 2018.

HODGES, Charles; MOORE, Stephanie; LOCKEE, Barb; TRUST, Torrev; BOND, Aaron. The Difference Between Emergency Remote Teaching and Online Learning, 2020. Disponível em: https:/ / er.educause.edu/articles / 2020/3/the-difference-between-emergency-remote-teachingand-online-learning. Acesso em 17 out. de 2020.

JUSTIN, Reich. Remote learning guidance from state education agencies during the COVID-19 pandemic: a first look. Disponível em: https://jwel.mit.edu/assets/document/remote-learning-guidancestate-education-agencies-during-covid-19-pandemic-first. Acesso em 17 out. de 2020.

MOREIRA, Darlinda; BARROS, Daniela Melaré Vieira. Orientações práticas para a comunicação sincrona e assincrona em contextos educativos digitais, 2020. Disponível em: http://hdl.handle.net/10400.2/9661. Acesso em 17 out. 2020.

MOREIRA, José António; HENRIQUES, Susana. BARROS, Daniela Melaré Vieira Transitando de um ensino remoto emergencial para uma educação digital em rede, em tempos de pandemia. Dialogia, São Paulo, n. 34, p.351-364, jan./abr., 2020. Disponível em:

https://www.researchgate.net/publication/341885804_Transitando_de_um_ensino_remoto_em ergencial_para_uma_educacao_digital_em_rede_em_tempos_de_pandemia. Acesso em 5 out. 2020.

MOREIRA, José António; HENRIQUES, Susana. BARROS, Daniela Melaré Vieira (coord.) Guia Pedagógico Semanal. Formação para a docência digital em rede. Universidade Aberta, 2020b.

RIBEIRO, Ana Isabel.; BARROS, Daniela Melaré Vieira. Pedagogia e Didática com as Tecnologias Digitais no Ensino Superior. Imprensa da Universidade de Coimbra: Coimbra, Portugal, 2019.

Recebido em: 30 nov. 2020/ Aprovado em: 12 dez. 2020

\section{Cite como}

\section{(ABNT NBR 6023:2018)}

CAMPOS, Fernanda Araujo Coutinho; PEREIRA, Rute. Formação de professores nas ilhas portuguesas Madeira e Açores: estratégias para o ensino remoto em tempos da COVID-19. Dialogia, São Paulo, n. 36, p. 396-410, set./dez. 2020. Disponível em: https://doi.org/10.5585/dialogia.n36.18823.

\section{American Psychological Association (APA)}

Campos, F. C., \& Pereira, R. (2020, set./dez.). Formação de professores nas ilhas portuguesas Madeira e Açores: estratégias para o ensino remoto em tempos da COVID-19. Dialogia, São Paulo, 36, p. 396-410. https://doi.org/10.5585/dialogia.n36.18823. 